\title{
Oral and Dental Health
}

RESEARCH ARTICLE

\section{Microbiological Evaluation of Biofilm Formation on the Fixed Twin Block Appliance: A Clinical Trial}

\author{
Vanashree Vilas Takane ${ }^{1 *}$, Roopa Jatti ${ }^{2}$, Kishore Bhat ${ }^{3}$, Divya Keshan $^{4}$, Kanhoba Keluskar and Amit $^{5}$ \\ Jaisinghani ${ }^{6}$
}

${ }^{1}$ Private Practitioner, Smilekart Dental Clinic, India

${ }^{2}$ Head of Department, K.L.E.V.K.I.D.S, JNMC Campus, India

${ }^{3}$ Professor, Department of Microbiology, Maratha Mandal Dental College, India

${ }^{4}$ Private Practitioner, K.L.E.V.K.I.D.S, JNMC Campus, India

${ }^{5}$ Dean, K.L.E.V.K.I.D.S, JNMC Campus, India

${ }^{6}$ Lecturer, Sinhgad Dental College and Hospital, India

*Corresponding author: Dr. Vanashree Vilas Takane, BDS, MDS, Private Practitioner, Smilekart Dental Clinic, C 304 Canopus, Kabra Galaxy, Brahmand, Off Ghodbunder Road, Thane west 400607, India, Tel: 9860566883

\begin{abstract}
Introduction: Fixed twin block-a fixed functional appliance, used in orthodontic therapy serves as a surface for microbial colonisation. The microorganisms organised as biofilms are protected from harmful environmental factors and an increased risk of disease may be its direct consequence.

Study design: Fixed Twin Block appliances of 21 healthy children among the ages of 11 to 15 years were taken to evaluate the different types of microorganisms associated with biofilm formation on this functional appliance at baseline, $1^{\text {st }}, 3^{\text {rd }}$ month and $6^{\text {th }}$ months. For isolation of microorganism from biofilms different types of selective and nonselective medium based on standard methods were used. The percentage frequencies of isolates were also calculated.

Results: Gram positive cocci- S. mutans, S. mitis and other Streptococcus sp., Gram-negative Facultative anaerobic rods of Enterobacteriaceae sp. like Enterobacter faecalis, Klebsiella pneumoniae, Escherichia coli, proteus, citrobactor, Obligate anaerobic rods- Porphyromonas gingivalis and Prevotella intermedia, Gram positive facultative anaerobic rods like lactobacilli and actinomyces; and Candida albicans were found in the samples. Statistically significant elevated levels of S. mutans, S. mitis, other streptococci, Actinomyces spp, Candida $s p$., E. coli with increase in time show peak values at six months except for $S$. mitis and other streptococci $s p$.
\end{abstract}

Conclusion: The employment of fixed acrylic based Twin Block appliance can represent a factor promoting the colonisation of the oral cavity by various micro-organisms and stresses the need of a careful monitoring of orthodontic patients for the risk of development of various plaque associated diseases and institution of preventive measures for the same.

\section{Keywords}

Acrylic, Biofilm, Streptococcus, Twin block

\section{Introduction}

Oral cavity is a rich ecosystem with a myriad of micro-organisms accounting for more than 800 distinct bacterial species [1,2]. Most organisms can only sustain in oral cavity when they adhere to either the hard or soft tissues where a biofilm is formed [3]. A biofilm is an assemblage of microbial cells that is irreversibly associated (not removed by gentle rinsing) with a surface and enclosed in a matrix of primarily extracellular polymeric material. The initial step in the colonization of these surfaces is bacterial adherence either to host tissues or biomaterials. The formation of multispecies biofilms is influenced by three major factors; The composition of the potential colonizing species that will make up the biofilm, the bulk fluid(s) that bathe and sustain the biofilm

Citation: Takane VV, Jatti R, Bhat K, Keshan D, Keluskar K, et al. (2018) Microbiological Evaluation of Biofilm Formation on the Fixed Twin Block Appliance: A Clinical Trial. Int J Oral Dent Health 4:066. doi. org/10.23937/2469-5734/1510066

Accepted: October 29, 2018: Published: October 31, 2018

Copyright: @ 2018 Takane VV, et al. This is an open-access article distributed under the terms of the Creative Commons Attribution License, which permits unrestricted use, distribution, and reproduction in any medium, provided the original author and source are credited. 
community, and the nature of the surface to which the biofilm adheres [3]. Acrylic appliances are often used in orthodontics which serve as a surface for microbial colonisation. Fixed twin block is one such appliance used in functional therapy in orthodontics, influences the facial skeleton of the growing child thereby intercepting the developing malocclusion [4]. Design of twin block constitutes of two separate acrylic plates for upper and lower arch with occlusal bite blocks bonded to the teeth by Glass ionomer cement (GIC). The performance of efficacious oral hygiene is hindered considering the young age of these patients leading to increased plaque retention. Dental caries, gingivitis, periodontitis, stomatitis are some of the plaque mediated diseases which occur as a result of proliferation of pathogenic strains that form part of biofilms [5]. Knowledge of the formation, composition of dental plaque is of paramount significance for the understanding of the pathogenesis of the potential disease processes associated with it and institution of appropriate preventive measures.

So the present research was conducted at KLE VK Institute of Dental Sciences in 2015 to evaluate microbial composition and changes in the biofilm associated with fixed functional appliance- twin block. The objectives of the study were to identify, enumerate, quantify and compare microorganisms associated with biofilm formation on the twin block appliance at baseline, one, three and six months.

\section{Material and Methods}

The study was approved by Research Ethical Committee KLE VK Institute of Dental sciences and written consent was obtained from the patient's parents. Patients requiring functional appliance therapy aged between 12-15 years were screened for inclusion and exclusion criteria and 23 subjects were included in the study. Of the 23 subjects initially enrolled in the study, 21 (91.3\%) participated. Inclusion criteria included cases in age group of 12 to 15 years with class II div 1 malocclusion requiring functional appliance therapy with twin block, healthy systemic and periodontal condition (depth of periodontal pockets $\leq 3 \mathrm{~mm}$ ) avoidance of antibiotic therapy and antiseptic mouthwashes during research period and three months before research, cases on vegetarian diet, cases with full dentition present till second molar teeth. Exclusion criteria included use of oral antimicrobials or antibiotics within past 3 months, presence of any other fixed prosthesis, previous history of orthodontic treatment, systemic disorders. Following appliance placement curette scrapings were collected from 1 square centimeter area of the buccal surfaces of upper acrylic plate of the appliance from the right side. All patients received precise instructions in oral hygiene regime (instructions in teeth brushing methods especially around the appliance for a minimum of 3 minutes three times a day) and dietary intake before

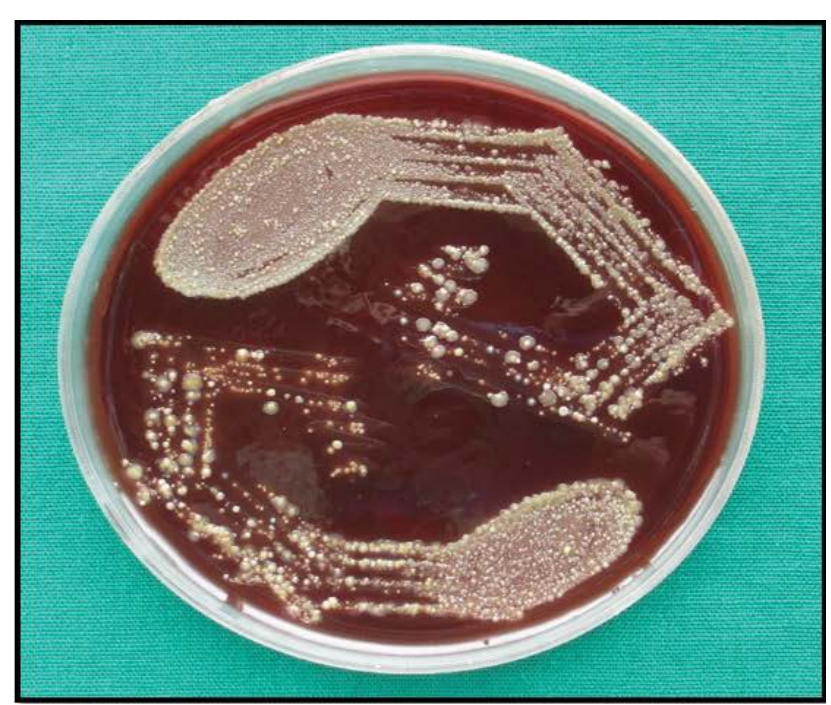

Figure 1: Blood agar plate showing streptococcus species.

functional appliance placement and during each recall. Patients were asked not to eat anything 2 hours prior to collection of scrapings and scrapings were collected in the time period of $10 \mathrm{am}$ to $12 \mathrm{pm}$. Scrapings from each subject were examined at baseline, $1^{\text {st }}$ month, $3^{\text {rd }}$ month and $6^{\text {th }}$ month.

One milliliter of $10 \mathrm{mmol} / \mathrm{L}: 1 \mathrm{mmol} / \mathrm{L}$ of Reduced transport fluid (RTF) added to a sterile tube under laminar airflow acted as transport media for the specimen. Samples were placed in tubes containing RTF. Within half an hour, the samples were mixed by using a vortex mixer for 30 seconds. Plating was done $50 \mathrm{uL}$ of the sample and were cultured aerobically and anaerobically in selective and non-selective media for the incubation period of 48-72 hours. The numbers of colony forming units per milliliter (CFU/mL) present were determined at 10-3 dilution (Figure 1 ).

\section{Statistical Analysis}

The data gathered was stored and analysed using the SPSS V statistical analysis program. Mean and standard deviation were calculated for each organism. Friedman test was carried out to compare the mean CFU difference of a particular organism at different time intervals.

\section{Results}

No growth was observed in $66.7 \%, 52.9 \%, 40.6 \%$, $31.2 \%$ of patients at baseline, one, three and six months respectively. S. mutans appeared at three months showed a statistically significant elevated values with a mean of 11.66 and 24.76 CFU $10-3$ at three and six months respectively. S. mitis showed statistical significant elevation till three months with a mean of 21.09 CFU 10-3 after which it showed slight decrease (mean of 20 CFU 10-3) Other Streptococci showed statistical significant elevated values till third month $(21.38,54$, 124.52 CFU 10-3 respectively) after which CFU count declined slightly to $110.06 \mathrm{CFU} 10-3 \mathrm{ml}$. Actinomyces 
Table 1: Descriptive statistics of the number of CFU of various bacteria in biofilm from twin block appliance at baseline $\left(T_{0}\right)$, one month $\left(T_{1}\right)$, three months $\left(T_{2}\right)$ and six months $\left(T_{3}\right)$ after placement of the appliances and $P$ values based on freidmann's nonparametric test.

\begin{tabular}{|c|c|c|c|c|c|}
\hline Organism & Timeline & $\mathbf{N}$ & Mean & Std. deviation & P-value \\
\hline \multirow[t]{4}{*}{ Proteus } & $\mathrm{T}_{0}$ & 1 & 0.0952 & 0.4364 & \multirow[t]{4}{*}{0.085} \\
\hline & $\mathrm{T}_{1}$ & 2 & 2.85 & 11.09 & \\
\hline & $\mathrm{T}_{2}$ & 6 & 23.333 & 50.30 & \\
\hline & $\mathrm{T}_{3}$ & 6 & 13.169 & 30.19 & \\
\hline \multirow[t]{4}{*}{ Klebsiella pneumonia } & $\mathrm{T}_{0}^{3}$ & 2 & 5.71 & 22.03 & \multirow[t]{4}{*}{0.260} \\
\hline & $T_{1}$ & 5 & 15.28 & 65.28 & \\
\hline & $T_{2}$ & 6 & 3.04 & 5.39 & \\
\hline & $\mathrm{T}_{3}$ & 7 & 5.62 & 10.32 & \\
\hline \multirow[t]{4}{*}{ E. coli } & $\mathrm{T}_{0}$ & 2 & 0.047 & 0.21 & \multirow[t]{4}{*}{$0.016^{*}$} \\
\hline & $T_{1}$ & 6 & 7.57 & 1866 & \\
\hline & $\mathrm{T}_{2}$ & 8 & 2.38 & 10.91 & \\
\hline & $\mathrm{T}_{3}$ & 6 & 22.38 & 52.91 & \\
\hline \multirow[t]{4}{*}{ Other streptococcus } & $T_{0}$ & 14 & 24.38 & 30.01 & \multirow[t]{4}{*}{$0.001^{*}$} \\
\hline & $T_{1}$ & 19 & 54 & 55.01 & \\
\hline & $T_{2}$ & 22 & 124.52 & 106.29 & \\
\hline & $\mathrm{T}_{3}$ & 20 & 110.06 & 79.29 & \\
\hline \multirow[t]{4}{*}{ S. mitis } & $\mathrm{T}_{0}$ & 6 & 3.14 & 5.91 & \multirow[t]{4}{*}{$0.015^{*}$} \\
\hline & $\mathrm{T}_{1}$ & 7 & 7.95 & 18.91 & \\
\hline & $\mathrm{T}_{2}$ & 13 & 21.09 & 28.90 & \\
\hline & $\mathrm{T}_{3}$ & 12 & 20 & 23.02 & \\
\hline \multirow[t]{4}{*}{ S. mutans } & $T_{0}^{0}$ & 0 & 0 & 0 & \multirow[t]{4}{*}{$0.001^{*}$} \\
\hline & $T_{1}$ & 3 & 0 & 0 & \\
\hline & $\mathrm{T}_{2}$ & 6 & 11.66 & 24.66 & \\
\hline & $\mathrm{T}_{3}$ & 6 & 24.76 & 48.64 & \\
\hline \multirow[t]{4}{*}{$P$. gingivalis } & $T_{0}$ & 2 & 0.19 & 0.60 & \multirow[t]{4}{*}{0.662} \\
\hline & $T_{1}$ & 4 & 0.95 & 3.12 & \\
\hline & $\mathrm{T}_{2}$ & 1 & 0.24 & 1.09 & \\
\hline & $\mathrm{T}_{3}$ & 2 & 0.28 & 0.90 & \\
\hline \multirow[t]{4}{*}{ Actinomyces } & $T_{0}$ & 7 & 7.28 & 14.48 & \multirow[t]{4}{*}{$0.001^{*}$} \\
\hline & $T_{1}$ & 9 & 10.47 & 21.50 & \\
\hline & $T_{2}$ & 13 & 29.66 & 44.34 & \\
\hline & $\mathrm{T}_{3}$ & 16 & 65.14 & 83.54 & \\
\hline \multirow[t]{4}{*}{ Lactobacilli } & $T_{0}$ & 0 & 0 & 0 & \multirow[t]{4}{*}{0.123} \\
\hline & $\mathrm{T}_{1}$ & 7 & 0.52 & 2.40 & \\
\hline & $\mathrm{T}_{2}$ & 4 & 11.95 & 29.87 & \\
\hline & $\mathrm{T}_{3}$ & 4 & 11.04 & 23.68 & \\
\hline \multirow[t]{4}{*}{ Candida albicans } & $\mathrm{T}_{0}$ & 0 & 0 & 0 & \multirow[t]{4}{*}{$0.004^{*}$} \\
\hline & $\mathrm{T}_{1}$ & 1 & 0.09 & 0.43 & \\
\hline & $\mathrm{T}_{2}$ & 3 & 1.85 & 6.59 & \\
\hline & $\mathrm{T}_{3}$ & 9 & 20.95 & 0.34 & \\
\hline Prevotella intermedia & $T_{1}$ & 2 & 0.28 & 0.95 & 0.135 \\
\hline Citrobacter & $\mathrm{T}_{3}$ & 2 & 2.38 & 10.91 & - \\
\hline \multirow[t]{2}{*}{ E. faecalis } & $\mathrm{T}_{2}$ & 1 & 4.76 & 21.82 & \multirow[t]{2}{*}{0.655} \\
\hline & $\mathrm{T}_{3}$ & 1 & 2.85 & 13.03 & \\
\hline Staphylococcus aureus & $\mathrm{T}_{1}^{3}$ & 1 & 0.476 & & - \\
\hline
\end{tabular}

*Statistically significant with $p<0.05$.

Table 2: Showing frequency of isolation of microbial species at baseline.

\begin{tabular}{|c|c|c|c|}
\hline Timeline & Organism & Frequency & Percent \\
\hline \multirow[t]{8}{*}{ Baseline $\left(T_{0}\right)$} & Proteus & 1 & 2.9 \\
\hline & Klebsiella pneumoniae & 2 & 5.9 \\
\hline & E. coli & 2 & 5.9 \\
\hline & Other streptococci & 14 & 41.2 \\
\hline & S. mitis & 6 & 17.6 \\
\hline & $P$. gingivalis & 2 & 5.9 \\
\hline & Actinomyces & 7 & 20.6 \\
\hline & Total & 34 & 100.0 \\
\hline
\end{tabular}

$s p$. showed statistically significant increase with mean of $7.28,10.47,29.66,65.14 \mathrm{CFU} 10 / \mathrm{ml}$ at baseline, one, three and six months respectively. Candida sp. appeared at one months and showed statistically significant elevation with mean values of $0.09,1.85,20.95$ at one, three and six months respectively (Table 1, Figure 2 and Figure 3).

The most common microorganisms isolated at baseline were the members of the family Other Streptococ- 


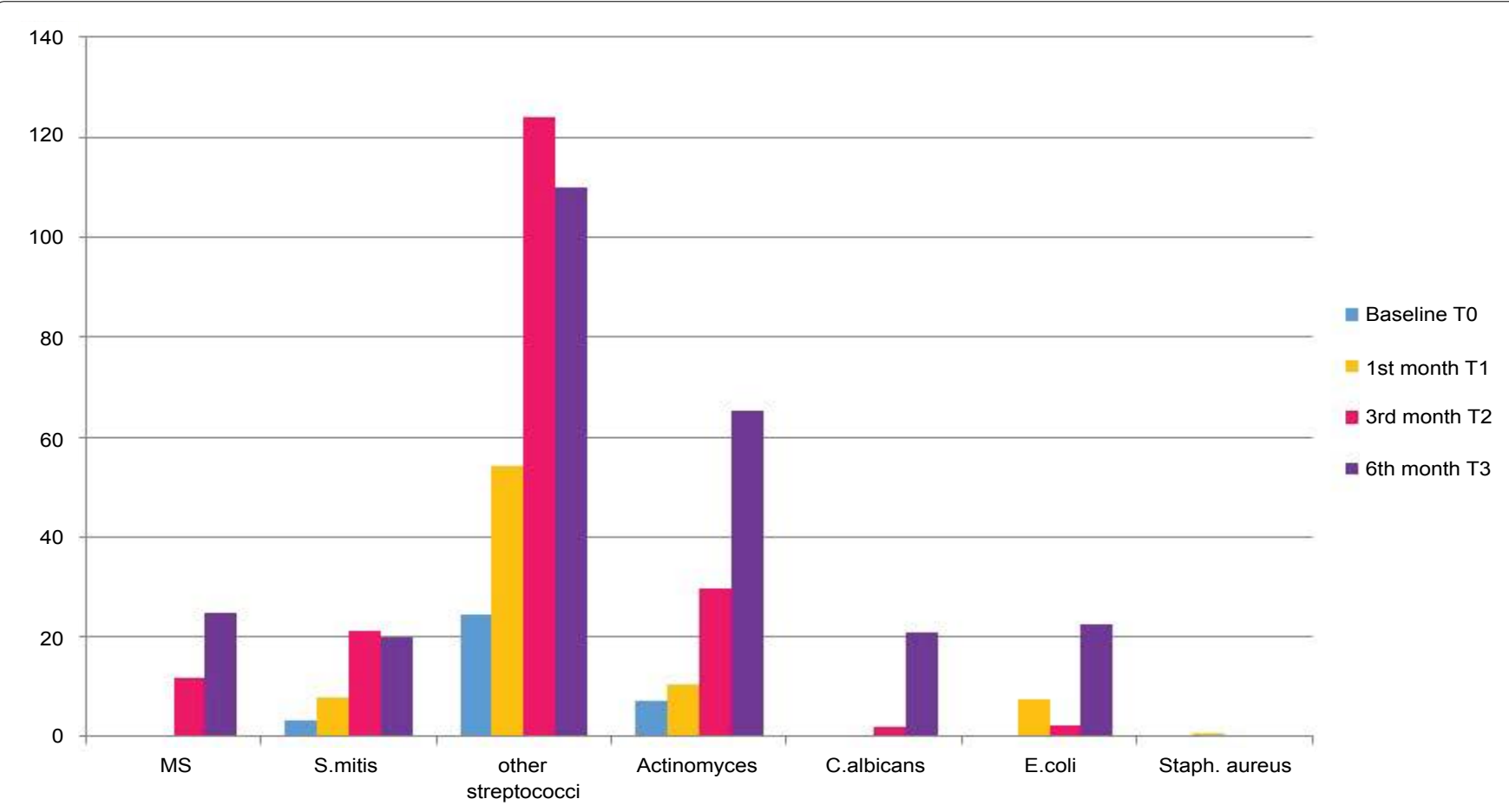

Figure 2: Graphical representation showing CFU 10-3 ml of mutans streptococci, streptococcus mitis, other streptococci, actinomyces, candida albicans, E. coli, staphylococcus aureus at T0, T1, T2, T3.

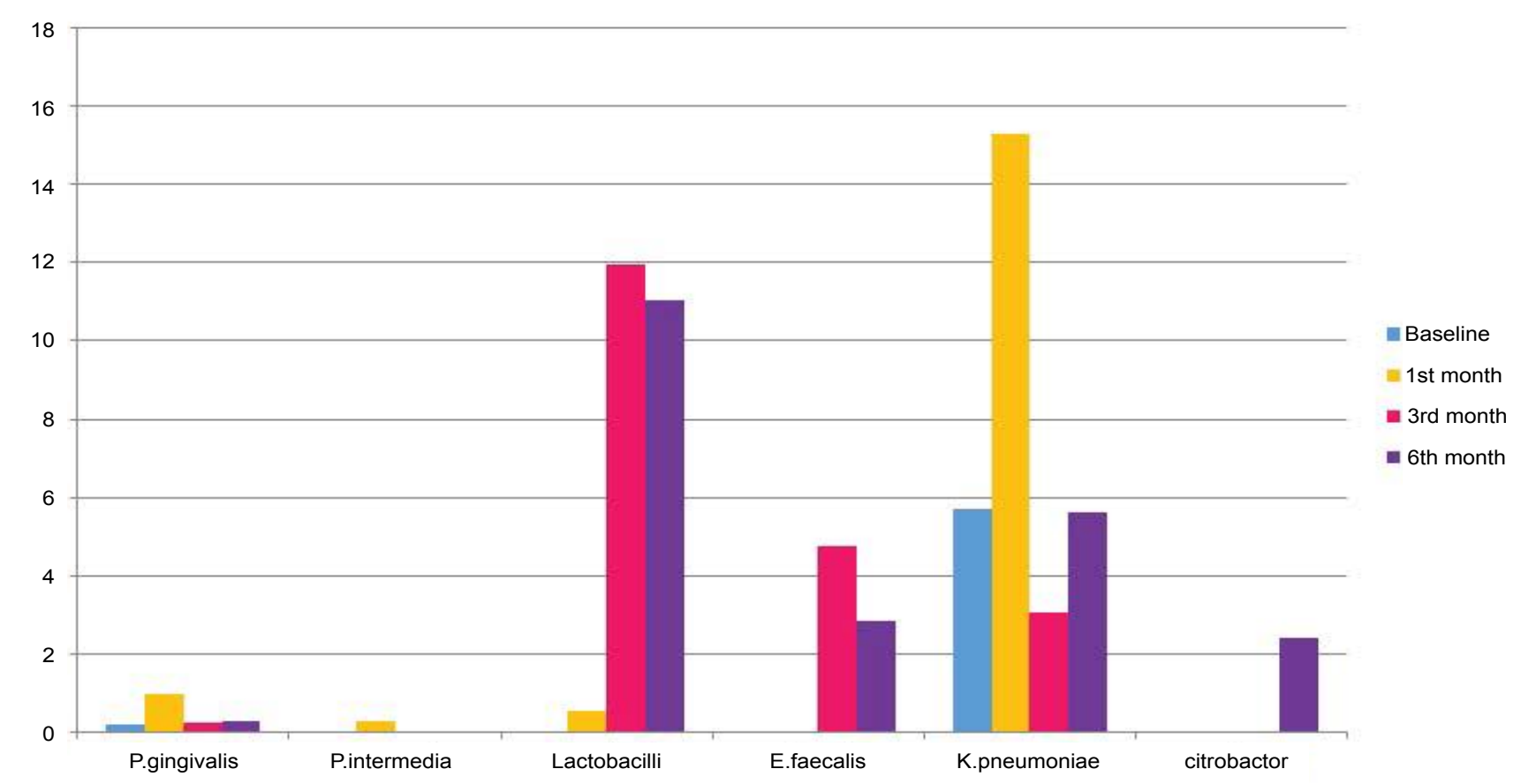

Figure 3: Graphical representation showing CFU 10-3 ml of porphyromonas gingivalis, prevotella intermedia, lactobacilli, enterobacter faecalis, klebsiella pneumoniae, citrobacter at T0, T1, T2, T3.

ci $41.2 \%$, Actinomyces sp. $20.6 \%$, S. mitis $17.6 \%$, Klebsiella pneumoniae, $E$. coli, and $P$. gingivalis $5.9 \%$ each followed by Proteus 2.9\% (Table 2 and Figure 4). The most common microorganisms isolated at one month were that of other Streptococci 31.7\%, Actinomyces sp. $15 \%$, S. mitis $11.7 \%$, E. coli $10 \%$, Klebsiella pneumoniae $8.3 \%$, P. gingivalis $6.7 \%$, S. mutans $5 \%$, Prevotella intermedia 3.3\%, lactobacilli, candida sp. and staphylococcus aureus 1.7 each (Table 3 and Figure 5). The most common microorganisms isolated at three months were of other Streptococci $25.88 \%$, Actinomyces sp. and S. mi- tis $15.29 \%$ each, E. coli $9.41 \%$, lactobacilli sp. $8.25 \%$, S. mutans and Proteus $7.05 \%$ each, Klebsiella pneumoniae $5.88 \%$, S. mutans 5\%, Prevotella intermedia 3.3\%, candida sp. $3.52 \%$ and $P$. gingivalis and E. faecalis $1.11 \%$ each (Table 4 and Figure 6) The most common microorganisms isolated at six months were Other Streptococci $21.97 \%$, Actinomyces sp. $17.58 \%$, S. mitis $13.1 \%$, S. mutans, E. coli and Proteus 6.59\% each, lactobacilli $s p$. 4.39\%, Klebsiella pneumoniae $7.69 \%$, candida sp. 3.52\%, P. gingivalis and Citrobacter 2.1\% each, E. faecalis 1.09\% (Table 5 and Figure 7). 
Table 3: Showing frequency of isolation of microbial species at one months.

\begin{tabular}{|l|l|l|l|}
\hline One month $\mathbf{( T}_{\mathbf{1}} \mathbf{)}$ & Proteus & 2 & 3.3 \\
\hline & Klebsiella pneumoniae & 5 & 8.3 \\
\hline E. coli & 6 & 10.0 \\
\hline Staphylococcus aureus & 1 & 1.7 \\
\hline Other Streptococci & 19 & 31.7 \\
\hline S. mitis & 7 & 11.7 \\
\hline S. mutans & 3 & 5.0 \\
\hline P. gingivalis & 4 & 6.7 \\
\hline Actinomyces & 9 & 15.0 \\
\hline Lactobacilli & 1 & 1.7 \\
\hline Candida albicans & 1 & 1.7 \\
\hline Prevotella intermedia & 2 & 3.3 \\
\hline Total & 60 & 100.0 \\
\hline
\end{tabular}

Table 4: Showing frequency of isolation of microbial species at three months.

\begin{tabular}{|l|l|l|l|}
\hline Third month $\left.\mathbf{( T}_{2}\right)$ & Proteus & 6 & 7.05 \\
\hline & Klebsiella pneumoniae & 5 & 5.88 \\
\hline E. coli & 8 & 9.41 \\
\hline Other streptococci & 22 & 25.88 \\
\hline S. mitis & 13 & 15.29 \\
\hline S. mutans & 6 & 7.05 \\
\hline P. gingivalis & 1 & 1.11 \\
\hline Actinomyces & 13 & 15.29 \\
\hline Lactobacilli & 7 & 8.25 \\
\hline Candida albicans & 3 & 3.52 \\
\hline E. faecalis & 1 & 1.11 \\
\hline Total & 85 & 100.0 \\
\hline
\end{tabular}

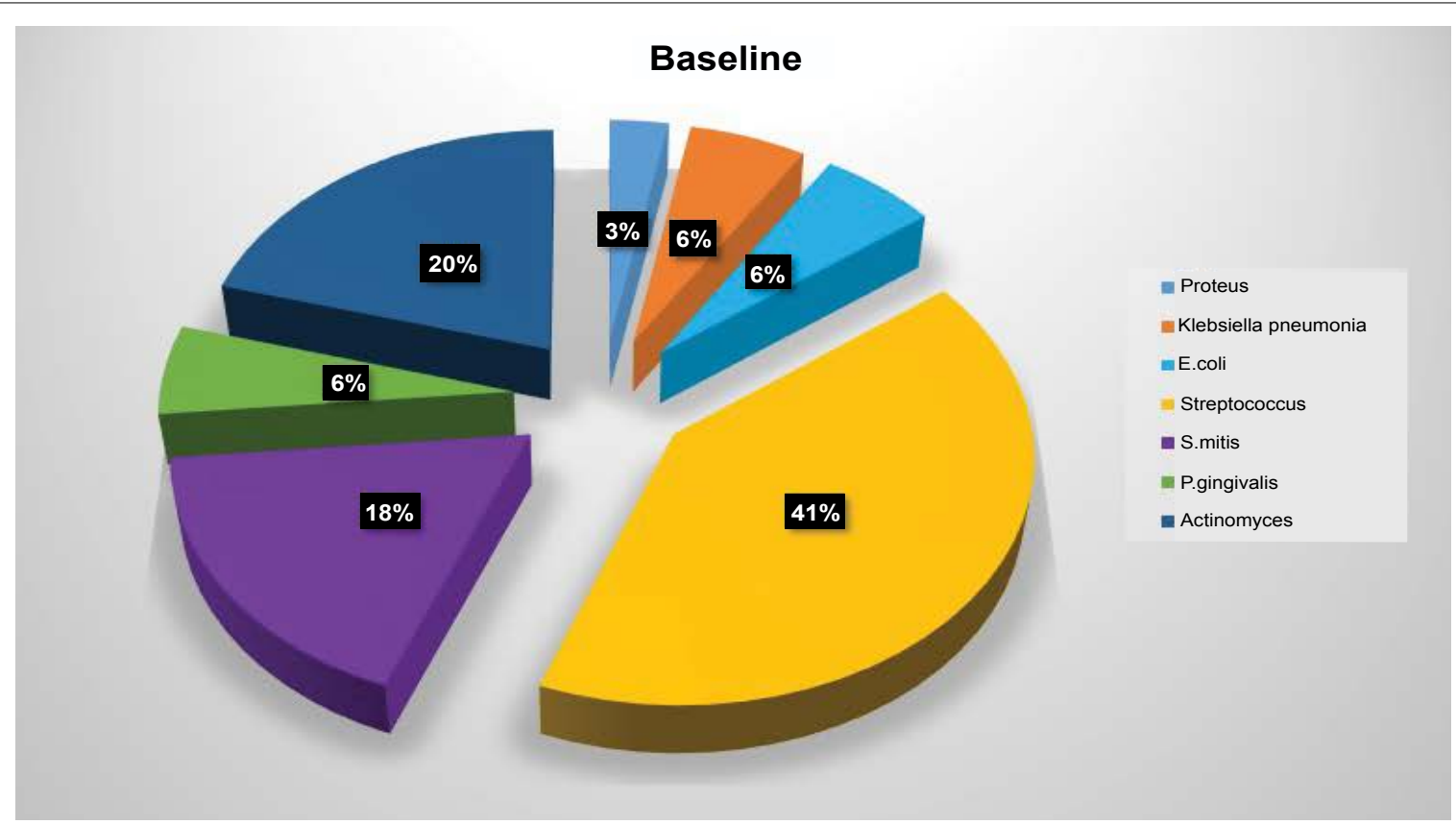

Figure 4: Diagram showing frequency of isolation of microbial species at baseline.

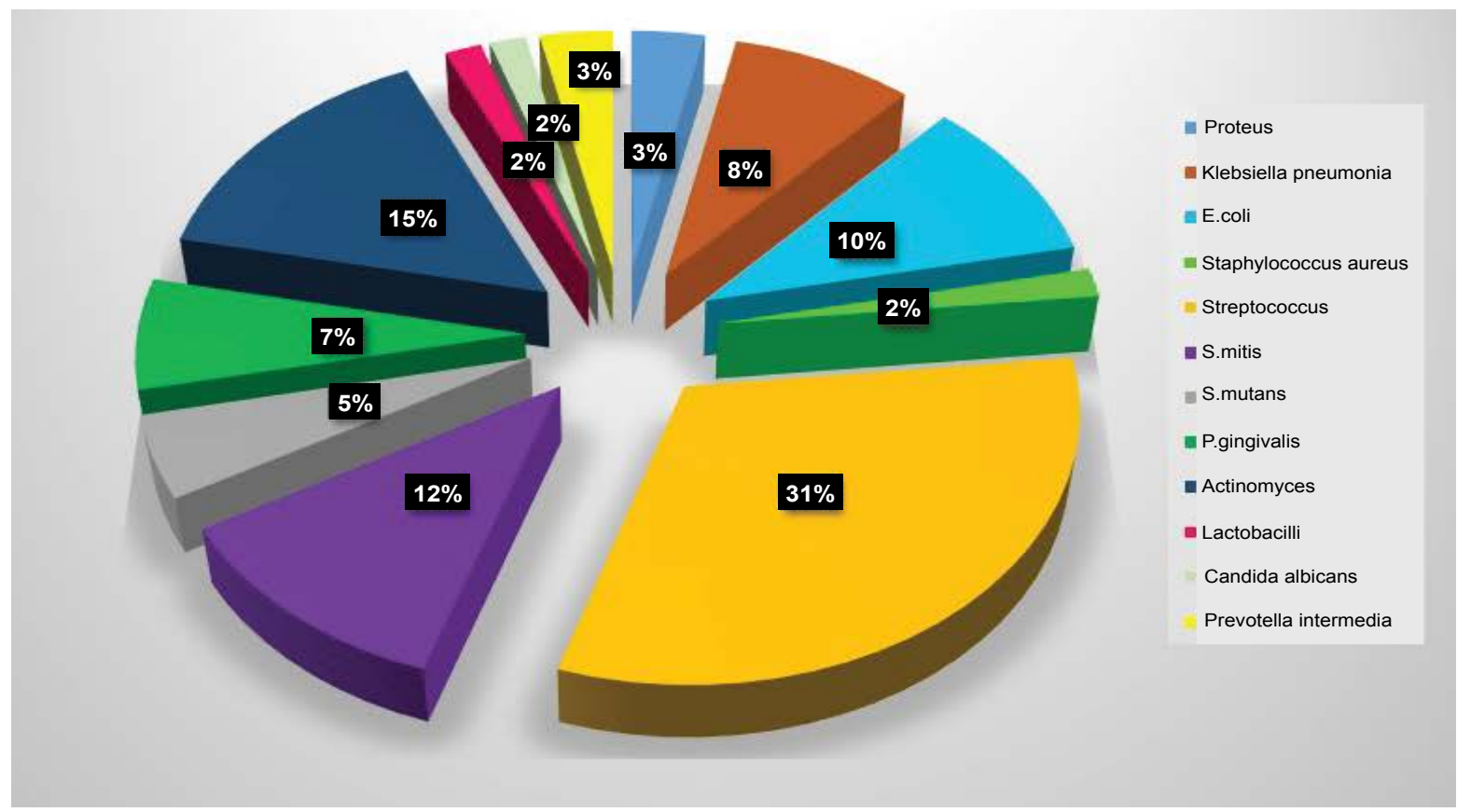

Figure 5: Diagram showing frequency of isolation of microbial species at one month. 


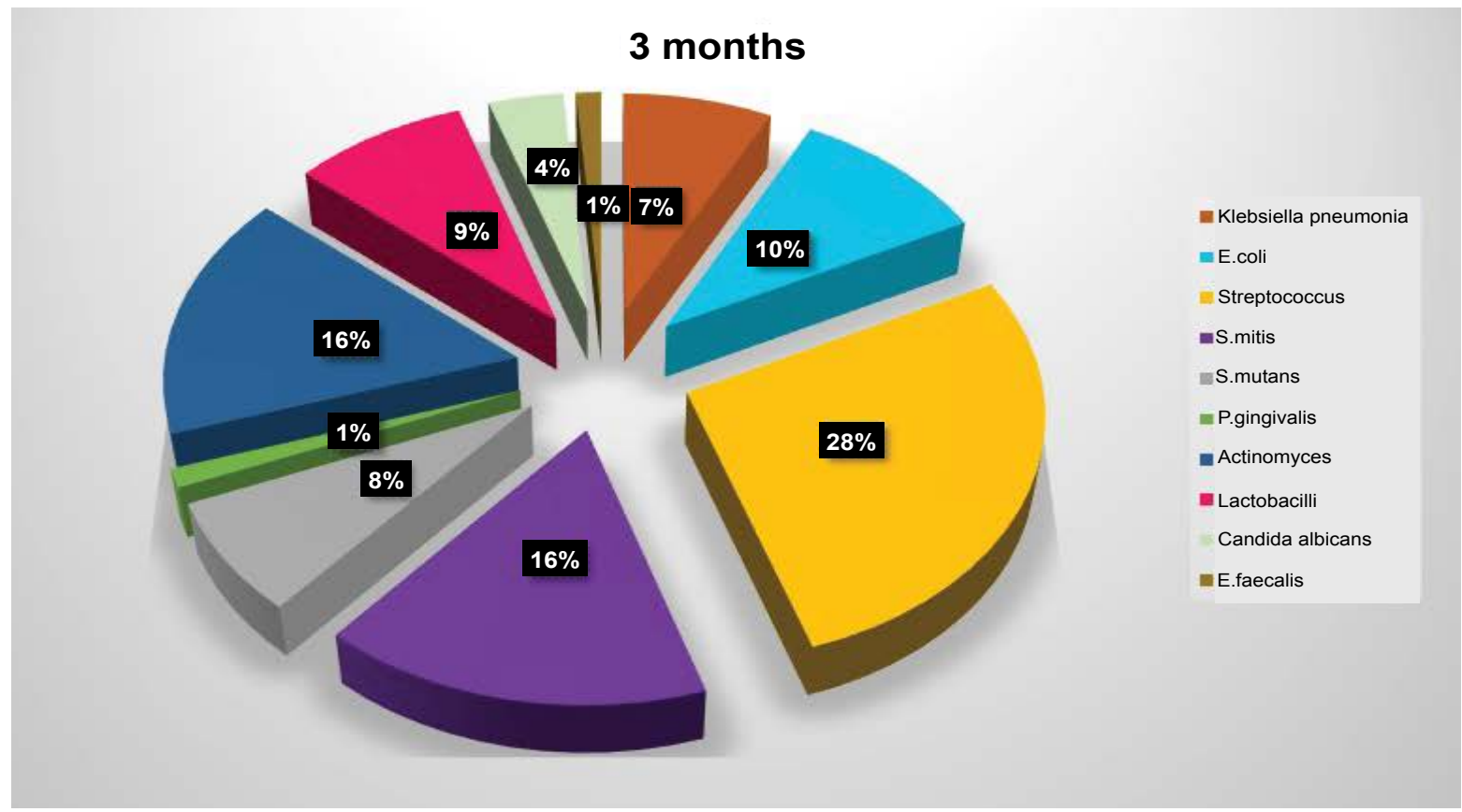

Figure 6: Diagram showing frequency of isolation of microbial species at three months.

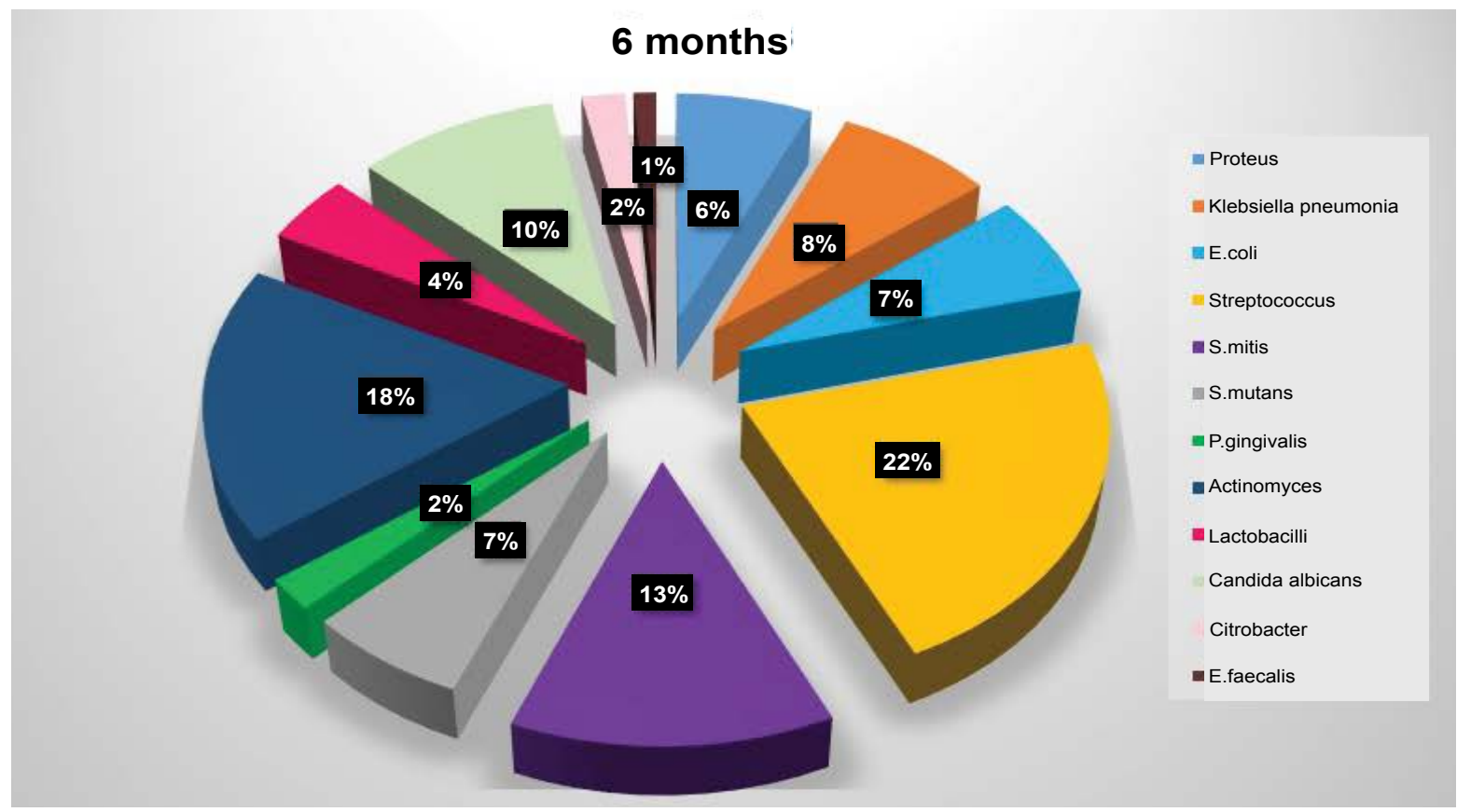

Figure 7: Diagram showing frequency of isolation of microbial species at six months.

Table 5: Showing frequency of isolation of microbial species at six months.

\begin{tabular}{|l|l|l|l|}
\hline Sixth month $\left(\mathbf{T}_{3}\right)$ & Proteus & 6 & 6.59 \\
\hline & Klebsiella pneumoniae & 7 & 7.69 \\
\hline E. coli & 6 & 6.59 \\
\hline Other streptococci & 20 & 21.97 \\
\hline S. mitis & 12 & 13.1 \\
\hline S. mutans & 6 & 6.59 \\
\hline P. gingivalis & 2 & 2.1 \\
\hline Actinomyces & 16 & 17.58 \\
\hline Lactobacilli & 4 & 4.39 \\
\hline Candida albicans & 9 & 9.8 \\
\hline Citrobacter & 2 & 2.1 \\
\hline E. faecalis & 1 & 1.09 \\
\hline Total & 91 & 100.0 \\
\hline
\end{tabular}

\section{Discussion}

Acrylic appliances used in orthodontics and dentofacial orthopaedics are in the form of functional appliances, retention plates, bite blocks, mouth guards etc. Sequential culturing (gold or primary standard) of the biofilms on these acrylic surfaces at different time points provide an insight into the alterations of oral microbiome. The culturing technique relies on the detection of viable organisms. Hence, immediate processing of samples upon acquisition were done to maximize bacterial survival under strict transport condition. The main advantages of this method are its capability to detect multiple bacterial species simultaneously; The 
possibility to obtain relative and absolute counts of the cultured species; and the fact that it is the only method that is able to detect unexpected bacteria, to properly characterize new species. Microorganisms cultured from high dilutions of suspensions of denture plaque were characterized. Kolenbrander proposed the phenomenon of "Coaggregation" wherein all oral bacteria have the potential to adhere to other species of oral cavity leading to the formation of multi-species biofilms in oral cavity $[6,7]$. Wide variation of microbial composition and quantity observed during this study is in accordance with previous investigations [8,9]. Our findings in respect of the predominance of various types of bacteria is in agreement with the results of an electron microscopic study by Divya Sharma, which showed that plaque on removable appliances consists mainly of Gram-positive cocci and short rods and has a structure similar to plaque found on natural tooth surfaces [10]. In the present study, Streptococcus species were prominent members of the flora with highest prevalence. Species of Mutans Streptococci have been implicated in the etiology of dental caries occurring on smooth surfaces. Statistically significant elevation in S. mitis, S. mutans levels show that Twin Block appliances may offer a reservoir for microorganisms associated with infections like bacterial endocarditis, aspiration pneumonia, gastrointestinal infections, etc. Also, candida sp. appeared during the first month reaching a peak mean at six months. Since their count exceeded the normal, it may be an increased risk factor for invasive candidosis when the host immune system is compromised. The black pigmented anaerobes such as $P$. intermedia, $P$. gingivalis and others which have been related to periodontal diseases were found in lesser amounts in the study. The possible reason for this could be the absence of increased oxygen tension required for growth of these organisms on the acrylic surfaces. Among the oral micro-organisms detected in our study, a range of Gram-negative bacteria like isolates of Klebsiella and Enterobacter are considered to be important producers of VSCs (volatile sulfur compounds) like hydrogen sulfide and methyl mercaptan responsible for oral halitosis [11]. Greatest prevalence of Other Streptococci (other alpha hemolytic streptococci like $S$. salivarius, $S$. sanguis, S. gordoni) at all time intervals supports their role as initial colonisers in formation of denture plaque as also observed in previous studies [12]. Streptococci levels peaked at three months followed by a reduction at six months. Possible explanation for this could be an increased salivary flow rate (buffering action) observed in patients after application of orthodontic appliances, dentures, and maxillary occlusal splints [13-15].

Acrylic surfaces act as a sponge with several porosities that might harbour microorganisms and debris. These acrylic surfaces are under mechanical stress that might cause surface imperfections ranging from microscopic fissures to defects visible to the naked eye like fractures, cracks, or gaps thus weakening the resin structure and providing a nidus for the retention, adherence and colonisation of microorganisms which predispose to bacterial biofilm accumulation, thus altering the normal oral microbial flora. Minagi, et al. have reported positive correlation between the surface free energies of acrylic surfaces and adherence of $C$. albicans [12].

Functional appliance therapy is usually followed by fixed mechanotherapy. So changes observed in oral microbial flora in this study are crucial and might account for their further alteration during the entire course of fixed orthodontic appliance treatment. Knowledge about the efficacy of different denture cleansing protocols can improve orientation for patients with orthodontic appliances. Acrylic surfaces can be cleaned mechanically, chemically, or through a combination of both. Since the Twin block appliance is fixed in the mouth for 6-9 months, immersion method cannot be used for disinfection. Superhydrophilic acrylic surfaces have been reported to reduce adherence of bacterial or fungal cells. Hence various modifications like surface treatment with Silica coating, application of NanoAg in situ in PMMA (Nanoparticles of silver), Heat post polymerization, etc can reduce bacterial adhesion [16-19].

Edvaldo Antonio Ribeiro Rosa, et al. have implicated a strong possibility that trauma following removal of Haas expanders might be correlated to transitory bacteremia associated with viridans streptococcus [20]. To reduce the complication of bacterial endocarditis in moderate to high-risk patients and considering the commonly seen increase in resistance to penicillin among viridans streptococci, an appropriate prophylactic approach during orthodontic procedures must be instituted. Erverdi N, et al. have proposed the use of mouth rinsing solutions such as chlorhexidine before removing the orthodontic bands [21]. Since the present study has shown elevated levels of viridans group of streptococci (S. mitis, S. mutans and other streptococci) explicit guidelines probably should be formulated post and prior to removal of acrylic based fixed orthodontic appliance.

Functional appliance therapy is usually followed by fixed mechanotherapy. So changes observed in oral microbial flora in this study are crucial and might account for their further alteration during the entire course of fixed orthodontic appliance treatment. According to Arneberg $50 \%$ to $70 \%$ of patients undergoing fixed orthodontic appliance therapy have demineralization areas on the enamel near the brackets (active white spot lesions) [22]. Various methods used to prevent enamel demineralization during fixed orthodontic treatment (daily use of $0.05 \% \mathrm{NaF}$, APF mouth rinse [23], sustained release chlorhexidine varnish [24]) can also be used during fixed Twin Block therapy. Other preventive measures like use of fluoride containing antibacterial adhesives, bonding agents, luting cements, elastomers may be considered during the fixed mechanotherapy. 


\section{Limitations}

Salivary flow rate, $\mathrm{pH}$, buffering capacity, dietary habits, racial differences, etc may act as confounding factors in this study indicating the influence of environmental, dietary, and genetic.

\section{Scope}

Detection and quantification of these specific statistically significant bacteria using recent advances in molecular techniques like Polymerase chain reaction (PCR) can be done. The effect of the adoption of disinfection protocols for fixed acrylic based orthodontic appliances is still unclear. Further studies with disinfection agents and methods are required.

\section{Conclusion}

Changes in microbial population with time are observed with Twin Block appliance therapy. There is a need for careful monitoring of orthodontic patients and taking specific preventive interventions against the risk of development of various plaque associated diseases especially during third month and sixth month of treatment.

\section{References}

1. Jorn A Aas, Bruce J Paster, Lauren N Stokes, Ingar Olsen, Floyd E Dewhirst (2005) Defining the normal bacterial flora of the oral cavity. J Clin Microbiol 43: 5721-5732.

2. Siqueira JF Jr, Rôças IN (2010) The oral microbiota: General overview, taxonomy, and nucleic acid techniques. Methods Mol Biol 666: 55-69.

3. Socransky SS, Haffajee AD (2005) Periodontal microbialn ecology. Periodontol 2000 38: 135-187.

4. William J Clark (2002) Twin block functional therapy application in dentofacial orthopedics. ( $2^{\text {nd }}$ edn), Elsevier Inc, New York.

5. Philip D Marsh (2006) Dental plaque as a biofilm and a microbial community-implications for health and disease. BMC Oral Health 6: 14.

6. William G Wade (2013) The oral microbiome in health and disease. Pharmacol Res 69: 137-143.

7. Kolenbrander PE, Andersen RN, Blehert DS, Egland PG, Foster JS, et al. (2002) Communication among oral bacteria. Microbiol Mol Biol Rev 66: 486-505.

8. Whittaker CJ, CM Klier, PE Kolenbrander (1996) Mechanisms of adhesion by oral bacteria. Annu Rev Microbiol 50: 513-552.

9. Shibly O, Rifai S, Zambon JJ (1995) Supragingival dental plaque in the etiology of oral diseases. Periodontol 2000 8: 42-59.

10. Pathak AK, Sharma DS (2013) Biofilm associated microor- ganisms on removable oral orthodontic appliances in children in the mixed dentition. J Clin Pediatr Dent 37: 335-339.

11. Goldberg S, Cardash H, Browining $H$, Sahly $H$, Rosenberg $M$ (1997) Isolation of enterobacteriaceae from the mouth and potential association with malodor. J Dent Res 76: $1770-1775$

12. S Minagi, Y Miyake, K Inagaki, H Tsuru, H Suginaka (1985) Hydrophobic interaction in candida albicans and candida tropicalis adherence to various denture base resin materials. Infect Immun 47: 11-14.

13. Miyawaki S, Katayama A, Tanimoto Y, Araki Y, Fujii A, et al. (2004) Salivary flow rates during relaxing, clenching, and chewing-like movement with maxillary occlusal splints. Am J Orthod Dentofacial Orthop 126: 367-370.

14. Yurdukoru B, Terzioglu H, Yilmaz T (2001) Assessment of whole saliva flow rate in denture wearing patients. $J$ Oral Rehabil 28: 109-112.

15. Moritsuka M, Kitasako Y, Burrow MF, Ikeda M, Tagami J, et al. (2006) Quantitative assessment for stimulated saliva flow rate and buffering capacity in relation to different ages. J Dent 34: 716-720.

16. Azuma A, Akiba N, Minakuchi S (2012) Hydrophilic surface modification of acrylic denture base material by silica coating and its influence on candida albicans adherence. J Med Dent Sci 59: 1-7.

17. Ahmad Sodagar, Bahareh Azizy, Mohammad Zaman Kassaee, Babak Pourakbari, Sepideh Arab, et al. (2013) Anti-cariogenic effect of polymethylmethacrylate with in situ generated silver nanoparticles on planktonic and biofilm bacteria. Annals of Biological Research 4: 211-219.

18. Marra J, Paleari AG, Rodriguez LS, Leite AR, Pero AC, et al. (2012) Effect of an acrylic resin combined with an antimicrobial polymer on biofilm formation. J Appl Oral Sci 20: 643-648.

19. Faltermeier A, Rosentritt M, Mussig D (2007) Acrylic removable appliances: Comparative evaluation of different postpolymerization methods. Am J Orthod Dentofacial Orthop 131: 301-322.

20. Rosa EA, Rached RN, Tanaka O, Fronza F, Fronza F, et al. (2005) Preliminary investigation of bacteremia incidence after removal of the Haas palatal expander. Am J Orthod Dentofacial Orthop 127: 64-66.

21. Erverdi N, Kadir T, Ozkan H, Acar A (1999) Investigation of bacteremia after orthodontic banding. Am J Orthod Dentofacial Orthop 116: 687-690.

22. Arneberg P, Ogaard B, Scheie AA, Rolla G (1984) Selection of streptococcus mutans and lactobacilli in an intra-oral human caries model. J Dent Res 63: 1197-1200.

23. Benson PE, Shah AA, Millett DT, Dyer F, Parkin N, et al. (2005) Fluorides, orthodontics and demineralization: A systematic review. J Orthod 32: 102-114.

24. Beyth N, Redlich M, Harari D, Friedman M, Steinberg D (2003) Effect of sustained-release chlorhexidine varnish on streptococcus mutans and actinomyces viscosus in orthodontic patients. Am J Orthod Dentofacial Orthop 123: 345-348. 